Document downloaded from:

http://hdl.handle.net/10251/72909

This paper must be cited as:

Torregrosa, AJ.; Bermúdez, V.; Olmeda González, PC.; Figueroa Garcia, OL. (2012).

Experimental assessment for instantaneous temperature and heat flux measurements under Diesel motored engine conditions. Energy Conversion and Management. 54(1):57-66. doi:10.1016/j.enconman.2011.10.009.

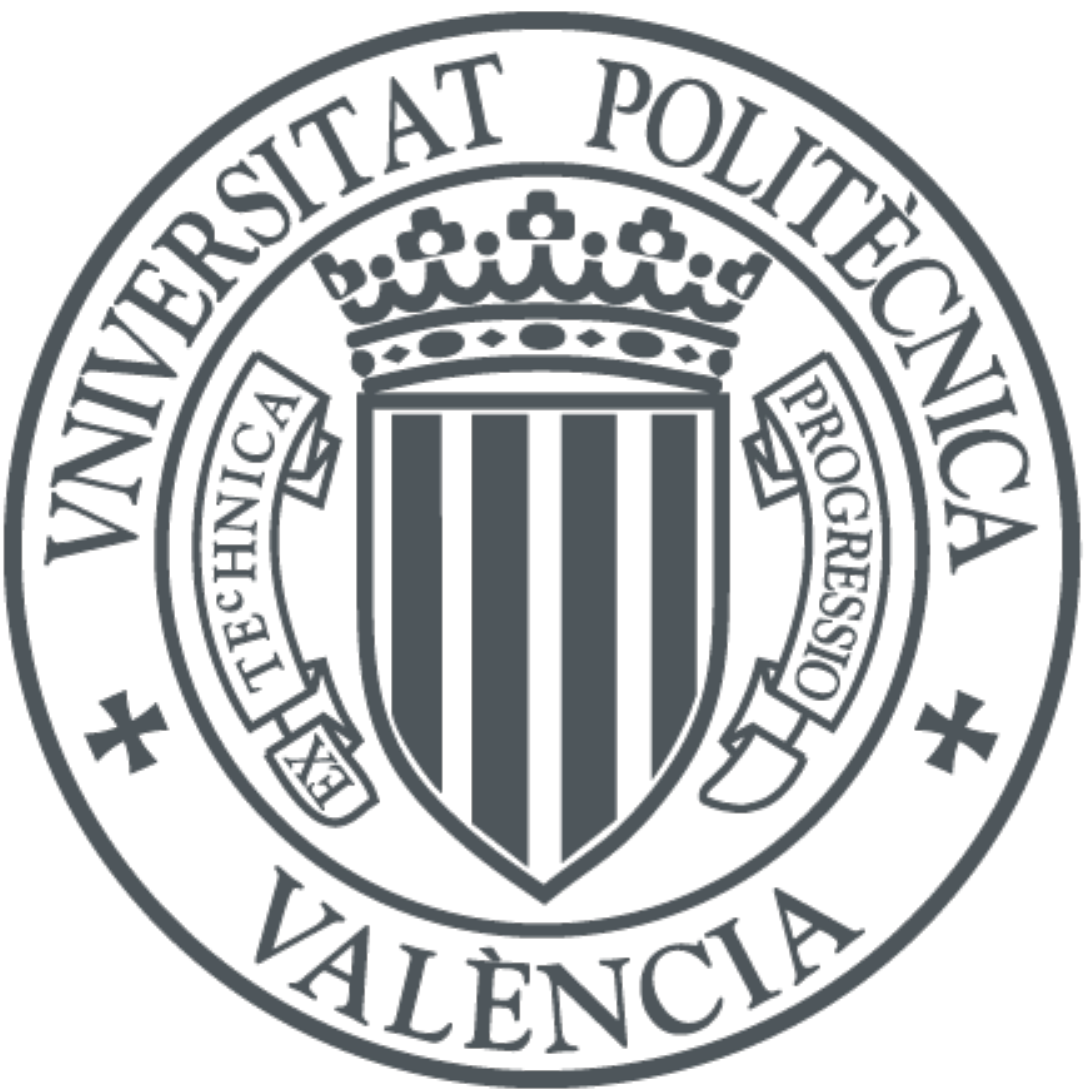

The final publication is available at

http://dx.doi.org/10.1016/j.enconman.2011.10.009

Copyright Elsevier

Additional Information 


\title{
Experimental assessment for instantaneous temperature and heat flux measurements under Diesel motored engine conditions
}

\author{
A.J. Torregrosa, V. Bermúdez, P. Olmeda, O. Fygueroa \\ CMT-Motores Térmicos, Universidad Politécnica de Valencia, Camino de Vera s/n, \\ 46022 Valencia, Spain.
}

\begin{abstract}
The main goal of this work is to validate an innovative experimental facility and to establish a methodology to evaluate the influence of some of the engine parameters on local engine heat transfer behaviour under motored steady-state conditions. Instantaneous temperature measurements have been performed in order to estimate heat fluxes on a modified Diesel single cylinder combustion chamber. This study was divided into two main parts. The first one was the design and setting on of an experimental bench to reproduce Diesel conditions and perform local-instantaneous temperature measurements along the walls of the combustion chamber by means of fast response thermocouples. The second one was the development of a procedure for temperature signal treatment and local heat flux calculation based on onedimensional Fourier analysis. A thermodynamic diagnosis model has been employed to characterise the modified engine with the new designed chamber. As a result of the measured data coherent findings have been obtained
\end{abstract}

\footnotetext{
*Corresponding author. Tel.: +34 (96) 3877650, fax: +34 (96) 3877659.
} 
in order to understand local behaviour of heat transfer in an internal combustion engine, and the influence of engine parameters on local instantaneous temperature and heat flux, have been analysed.

Keywords: Diesel engine, transient heat flux, local wall temperature, fast response thermocouples. 


\section{Nomenclature}

Latin:

$A_{n}, B_{n} \quad$ Fourier coefficients $\ldots \ldots \ldots \ldots \ldots \ldots \ldots \ldots \ldots \ldots \ldots \ldots \ldots \ldots \ldots$

$C_{w 1} \quad$ Woschni coefficient $\ldots \ldots \ldots \ldots \ldots \ldots \ldots \ldots \ldots \ldots \ldots \ldots \ldots \ldots \ldots$

$n \quad$ Harmonic number $\ldots \ldots \ldots \ldots \ldots \ldots \ldots \ldots \ldots \ldots \ldots \ldots \ldots$

$N \quad$ Number of harmonics $\ldots \ldots \ldots \ldots \ldots \ldots \ldots \ldots \ldots \ldots \ldots \ldots$

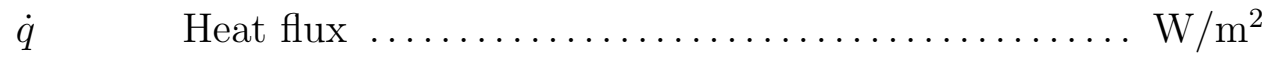

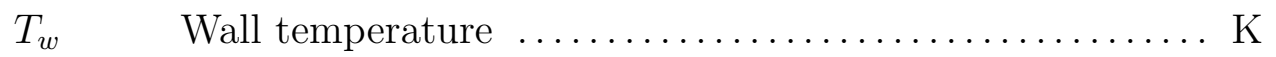

$T_{x} \quad$ In-depth temperature $\ldots \ldots \ldots \ldots \ldots \ldots \ldots \ldots \ldots \ldots$

$T_{m} \quad$ Time average value of wall temperature $\ldots \ldots \ldots \ldots \ldots$

$T_{i} \quad$ Temperature at different locations $(i=1$ to 5$) \ldots \ldots \ldots \mathrm{K}$

$x \quad$ Distance from in-depth and tip thermocouples $\ldots \ldots \ldots m m$

Abbreviations:

BDC Bottom dead centre

CAD Crack angle degrees

CFD Computational fluid dynamics

emf Thermocouple electromotive force

EVC Exhaust valve closing

IVC Inlet valve closing 
LHR Low heat rejection

NIST National institute of standards

RoHR Rate of heat release

rpm Revolutions per minute

TDC Top Dead Centre

Greek symbols:

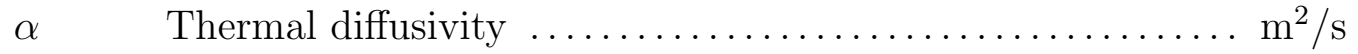

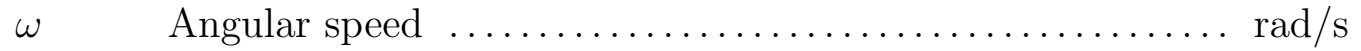

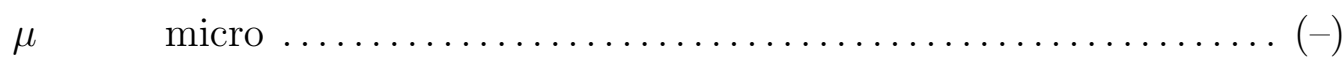




\section{Introduction}

From the beginning of Diesel engine development, the importance of understanding the heat transfer through the combustion chamber walls has been recognised [1-3]. Although this phenomenon is difficult to analyse because of its complexity, it that involves transient three dimensional behaviour, rapid temperature swings, piston motion, cooling passages, and turbulent reactive fluid dynamics, among others [4], it cannot be ignored.

Most of the studies performed in this area have been motivated by the influence of heat transfer on engine performance. Higher heat transfer rates to the combustion chamber walls will lead to a reduction of the mass average in cylinder temperature and pressure, and therefore the work per cycle transferred to the piston will be lower. As a consequence, specific power, engine fuel consumption and efficiency will be affected by the magnitude of engine heat transfer [5]. Concerning this, some investigations have been focused on the developement of adiabatic engines, covering the combustion chamber walls with ceramic coatings [6] or manufacturing them with materials with extremely high thermal resistance [7], so that the heat losses are reduced and recovered to be partially converted into useful work. These engines are commonly known as Low Heat Rejection (LHR) engines [8].

The important role that the preservation of the atmospheric environment plays in the society nowadays is well-known. Heat transfer knowledge is important in this suit as changes in gas temperature due to in-cylinder heat losses to the walls strongly affect emissions formation and after burning processes [9]. Additionally, in recent years, emissions regulations have become more restrictive while high-efficiency is still being demanded [10]. Some im- 
provements in cooling system design and strategies have been also considered in order to reduce emissions [11-14].

Finally it is also recognised the influence that engine heat transfer estimations have on the successful development of combustion diagnosis models, widely used by engine manufacturers during the early stages of engine design, in order to determine thermal loads and stresses $[15,16]$.

All these reasons have motivated a large amount of studies in the last decades aiming of a deeper understanding of engine heat transfer. Some of them are based on simple resistive models [18]. Some others are focused on the development of correlations to estimate heat transfer rates based on the theory of forced convection in turbulent flows [19], which can be time and locally averaged [20], instantaneous but spatially averaged [3, 21, 22], and those allowing for changes not only with time but also with location [23, 24]. In recent years, with the increasing use of computational fluid dynamics software (CFD) studies of temporal and spatial variation of the heat transfer coefficient inside the combustion chamber had also been reported [26-28].

Although all the theoretical work described above is valuable, experimental data is needed in order to validate the results, in the case of correlations, and to determine the initial and boundary condition values in the case of CFD codes for more accurate calculations [29, 30]. With this purpose significant efforts have been devoted to develop increasingly precise, fast, and robust sensors [31-33]. Most of the experimental studies in this field make use of high-frequency thermocouples, because of its low cost and fast response [34-36]. If temperature is measured on the piston the signal is transmitted by means of telemetry systems [37]. 
The main goal of this paper is to set up and validate an innovative experimental facility, and the corresponding methodology, to perform reliable studies on local Diesel engine heat transfer behaviour. In order to accomplish this, a well controlled bench was built that reproduces in-cylinder Diesel conditions, and a robust measurement system was set up, including fast response thermocouples for instantaneous temperature measurement at the same time that a protocol of measurement was established.

A compact procedure was written as a routine into a commercial code in order to perform temperature signal filtering and local heat flux calculations through the walls based on one-dimensional heat conduction theory with Fourier analysis. Additionally a thermodynamic diagnosis model was used to characterise and process the in-cylinder pressure signal.

This paper has been organised as follow: the next section presents a detailed description of the experimental facility, including the special requirements to measure instantaneous heat fluxes through the walls of the modified combustion chamber and the data acquisition system. In section three, the methodology is described, and temperature signal processing tools and mathematical methods for local heat flux calculation are described together with a brief description of the method used to characterise the engine with the thermodynamic model. Then, the experimental results obtained are discussed in the fourth section. Finally, some conclusions of the findings obtained throughout the whole development of the work are pointed out. 


\section{Experimental facility}

A fully equipped experimental cell has been designed with the aim of reproducing the thermodynamic conditions in a single cylinder Diesel engine, in order to evaluate the instantaneous heat fluxes through the walls. Special care has been taken not only in the configuration and control of the variables but also on the selection of the measurement equipment. A single cylinder, water cooled, two valve, direct injection Diesel research engine was chosen to perform these studies as this type of engines permit better control and management. Constructive characteristics and additional technical data of the engine are given in Table 1.

\subsection{Engine Modifications}

Carrying out instantaneous wall temperature measurements at different locations on the combustion chamber of an engine is complex due to piston motion and geometric characteristics, which include cooling passages throughout engine block and head. Thus, some modifications were made to the original engine. The original bowl was filled, obtaining a flat piston. Between the head and the cylinder block an extension of steel F114 was placed, in whose centre a combustion chamber was machined. A simplified sketch of the final combustion chamber configuration is shown in Figure 1.

For the design of this feature some considerations were taken into account. On the one hand it must be capable of reproducing in-cylinder conditions, by keeping as possible the compression ratio, allowing the opening and closing of intake and exhaust valves and enclosing the injector sleeve. On the other hand, the fitting of heat flux sensors must be easier than in a conven- 
tional combustion chamber, while permitting measurements on different wall locations of the chamber.

Subsequent to an evaluation of different designs and an optimisation process, the solution that better fulfilled all the main requirements was selected. Figure 2 shows the chosen solution and the final appearance of the in-house built elongation piece. It can be observed that the extension piece can be instrumented with heat flux sensors at different locations, one near the intake valve zone, one near the exhaust valve zone, and the other three in different positions along the central zone of the combustion chamber walls, where different temperature swings are expected, as a consequence of chamber geometry that produces dissimilar local conditions. A hole to place a pressure transducer was also machined in the middle zone of the combustion chamber.

As a consequence of engine modifications and experimental requirements, some changes had to be done on engine lubrication and cooling systems. First of all both systems must be external and split up as the piece between the head and the cylinder block does not allow the pass of any of the two liquids between them. It is also necessary to set, control and regulate initial wall temperatures in all tests an thus coolant circuit with temperature, pressure, and flow rate control was installed.

\subsection{Test bench}

A sketch of the experimental facility, data acquisition, and monitoring system is given in Figure 3. The engine was set to be motored under steadystate conditions connecting the crankshaft to an asynchronous dynamometer (Schenk LI 145) and torque was controlled and registered with a torque flange. In-cylinder pressure was measured with a piezoelectric transducer 
(Kistler 6055Bsp) connected to an amplifier (Kistler 5011) and registered with 0.5 crank angle resolution. Synchronisation between pressure signal and instantaneous crankshaft angle was performed by an optical encoder (AVL 1203).

Air was supplied to the engine by means of a screw compressor, which could set the inlet pressure from 1 to 2.5 bar. Once the air is compressed, passes through a liquid-gas heat exchanger, dryer and finally a filter. Afterwards air mass flow measurement was simultaneously performed via two flow meters: a hot wire anemometer (Sensyflow Sensycon Siemens) and a volumetric mass flow meter downstream located (ELSTER 75034124). These two measurement methods were used for various reasons. The hot wire anemometer allows proper measurements of low mass flows when the single cylinder engine is operating at low speed, whereas, the volumetric meter was used in tests with higher mass flow values. Additionally this permits to control the proper behaviour of the hot wire meter and to benefit measurement accuracy and avoid uncertainties in the cases where both systems were able to measure. Finally, the air passes through a settling chamber to prevent pulses generated by the intake process and a second heater before entering into the engine.

Air temperature and pressure were measured at different locations along the intake circuit with $\mathrm{K}$ type thermocouples and glow-plug piezoresistive pressure transducers. Air temperature was controlled via a PID with measurement performed a few millimetres upstream of the intake valve. This ensured that the intake temperature was as close as possible to the set value at the very entrance of the engine. Air pressure was also controlled via PID 
but it was measured in the settling chamber in order to avoid signal fluctuations.

Exhaust path consisted of a filter installed upstream of the settling chamber, where temperature and pressure were measured. The settling chamber was used, as it was say before, to reduce pressure fluctuations that can alter the measurement accuracy. A valve was installed at the end of the exhaust circuit to control back pressure. Finally blow-by mass flow was measured with a diaphragm-type flow meter (AVL 442) placed in a small tank connected to the oil pan.

As it can be seen several variables need to be measured and controlled. Short term response parameters need to be measured and registered with a very high sampling frequency (instantaneous measurements) while others can be measured and controlled with a longer response (in-depth temperature), or even average values (mean variables).

\subsection{Instantaneous temperature measurements}

With the aim of measuring in cylinder wall temperature variations, fast response, E-type, eroding thermocouples were employed as its response time is less than $10 \mu \mathrm{s}$ [38] making them very suitable for in cylinder applications. In order to measure the steady term of in-depth temperature, E-type thermocouples were also chosen. The reason of the choice was to obtain the maximum voltage change per degree.

The special heat flux probe used in these studies was built by NANMAC. It consists on a fast response eroding thermocouple on the tip of the probe and a common E-type in-depth thermocouple placed at a distance of 5 millimetres. Figure 4 shows a schematic draw of the probe. The two wires of 
dissimilar metals are flattened into thin ribbons. Then both metals are electrically insulated from each other with a very thin sheet of dielectric material forming a sandwich. Afterwards the excess of material is machined off and the tip surface is polished by an abrasive action [33]. This process forms microscopic welded measuring junctions, joining one ribbon to the other. Finally, surface and in-depth thermocouples are placed in a cylindrical house constructed with the same material as that of the wall and located in the combustion chamber.

The voltage obtained from the five fast response thermocouples was independently amplified and afterwards registered. Before signal amplification, all wires pass through an isothermal block, ensuring that the reference temperature is the same for the five probes. A platinum resistance was used to read the junction temperature which is stored for every test. Once all the signals were recorded, the emf corresponding to the junction temperature was calculated by means of the E type NIST polynomial equation and corrections were performed to each voltage via software. In depth temperature was measure with a device that has internal compensation, and does not need amplification.

Each flux sensor was flush mounted on the walls of the combustion chamber by means of a conical compression fitting that fixed it and avoided any gas loss from the combustion chamber. For better understanding during result discussion probes were numerated (Figure 2(a)). The one near the intake valve has been called $T_{2}$, and the one near the exhaust valve is called $T_{5}$. The other three are in the middle zone of the chamber: $T_{1}$ is nearby the intake zone, $T_{4}$ nearby the exhaust zone and $T_{3}$ is most centrally situated on the 
combustion chamber.

\section{Methodology and processing tools}

The methodology established and followed in order to evaluate the influence of engine operation parameters on the instantaneous heat transfer, combines experimental procedures and two analysis tools: an in-cylinder thermodynamic model based on signal pressure to characterise the new configuration (CALMEC [39]) and the calculation of local heat fluxes from instantaneous wall temperature measurements and Fourier analysis. Figure 5 shows a simplified flowchart of the methodology.

\subsection{Engine measurement methodology}

With the aim of performing parametric studies of the operating conditions, a matrix of 40 experiments was performed under motored steady-state conditions. It is important to remark that these studies were used also to characterise the modified engine, so that an extensive sweep was tested. Five levels of engine speed variation were consider $(1000,1500,2000,2500,3000$ $\mathrm{rpm})$, intending to cover all the engine operation range. The effect of inlet pressure was assessed by considering four levels of variation; the selection of the values was done from the minimum value corresponding to natural aspiration up to the maximum value that the compressor can reach by steps of 0.5 bar $(1,1.5,2,2.5)$. Finally, in order to estimate the possible fluctuation introduced to the heat flux due to the inner wall temperature, two temperatures were consider in the cooling and lubricating systems, $60^{\circ} \mathrm{C}$ and $70^{\circ} \mathrm{C}$. The test matrix is summarised in Table 2 . 
The protocol established in order to measure each point of the matrix was to motor the engine to the corresponding speed, until all the parameters were stabilised (intake air temperature, engine block temperature, and intake and exhaust pressure). During this period, steady state temperature was continuously measured until a constant value was obtained. Once all parameters were stable, instantaneous data were recorded on an angular base for twenty five thermodynamic cycles, and all mean variables were recorded simultaneously. Each point was measured three times in order to avoid uncertainties on the data.

\subsection{Thermodynamic diagnosis model}

CALMEC is an in-house diagnosis model firstly developed to calculate the rate of heat release (RoHR) and the temporal evolution of in-cylinder thermodynamic conditions from the instantaneous pressure signal. Despite the main objective of the model is to work with combustion test, there are some variables that determine the precision of the final results that can be obtained only from motored tests. This process is called engine characterisation and is necessary to perform it, if any modification of the engine can lead to a new compression ratio, a different deformation coefficient or different thermodynamic delay.

The procedure performed to engine characterisation is based on an iterative adjustment of the heat losses by two methods: in one the first law is solved, assuming that RoHR is zero and rejecting the term involving fuel energy as no combustion is performed. The other one is related to the model proposed by Woschni adjusting $C_{w 1}$ taking pressure as the reference value to conclude the iteration. It is to be noticed that even if pressure is the param- 
eter selected as a criterion for convergence, all the other parameters involved in the calculation are simultaneously adjusted (mass flow rate, blow-by coefficient, compression ratio, thermodynamic delay, and deformation coefficient)

\subsection{Instantaneous heat flux calculation}

A time periodic heat conduction model is used to estimate the local heat transfer, assuming that in the normal direction of the combustion chamber wall this heat transfer is strictly one dimensional, that material properties remain constant during an engine cycle, and that the internal and external temperatures are uniform at the start of the test. These assumptions are justified by the fact that the transient temperature penetrates only a small distance from the combustion chamber surface. The transient heat flux calculation can be performed by solving the unsteady heat conduction equation.

$$
\frac{\partial T}{\partial t}=\alpha \frac{\partial^{2} T}{\partial x^{2}}
$$

where $x$ is the distance between the surface and the in-depth thermocouple (5mm), and $\alpha$ is the thermal diffusivity of the material.

Boundary conditions for equation (1) are derived from the experimental temperature data and can be written as:

$$
T(0, t)=T_{w}(t)
$$

and

$$
T(x, t)=T_{x}=\text { constant }
$$

As the phenomenon can be assumed to be periodic and the thermal properties remain constant, the surface temperature $T_{w}(t)$, can be expressed by 
Fourier analysis [4] as:

$$
T_{w}=T_{m}+\sum_{n=1}^{N}\left[A_{n} \cos (n \omega t)+B_{n} \sin ((n \omega t)]\right.
$$

where $\omega$ is the angular frequency, $T_{m}$ is the time average value of $T_{w}, A_{n}$ and $B_{n}$ are the Fourier coefficients, $n$ the harmonic number and $N$ is the total number of harmonics.

In order to determine, $A_{n}$ and $B_{n}$, Fast Fourier Transform (FFT) was applied to the measured surface temperature. It is important to adequately select the value of the number of harmonics $N$ since if it is too small, the periodic temperature contour will not match the measured value accurately, and if it is too large, the signal will be disturbed with noise and this could lead to unphysical fluctuations in the profile [35]. In this work $N$ was chosen by applying a low pass filter based on a statistical method [40] to each location temperature signal.

Once $A_{n}$ and $B_{n}$ are determined, the instantaneous heat flux is calculated using the Fourier's law. Total heat flux will consist of a time-independent steady term and a time dependent transient term.

$$
\dot{q}=\frac{k}{x}\left(T_{m}-T_{x}\right)+k \sum_{n=1}^{N} \phi_{n}\left[\left(A_{n}+B_{n}\right) \cos (n \omega t)-\left(A_{n}-B_{n}\right) \sin (n \omega t)\right]
$$

where $\phi_{n}=\sqrt{(n \omega / 2 \alpha)}$ and $\dot{q}$ is total heat flux in $W / m^{2}$.

\section{Results and discussion}

In this section the results obtained from the tests indicated in the methodology will be presented and analysed. The effect of each of the parameters 
evaluated is independently presented as subsections as well as the validation of the modified engine.

\subsection{Engine validation}

All the tests performed in order to evaluate the intake and engine parameters were used to characterise the experimental facility. With the aim of validating the experimental facility, two sets of motored test were carried out. The first set was performed with the original configuration whit the bowl-in-piston combustion chamber, and the second with the modified combustion chamber and flat piston configuration. Intake temperature and pressure were set to be the same for the two groups of tests, as well as the exhaust pressure and oil and water temperature. Then the characterisation procedure of CALMEC was used to process the pressure signals and to calculate compression ratios and thermodynamic delays among other thermodynamic parameters.

Figure 6 presents a comparison between the original and modified pressure signal for a motored test with $25^{\circ} \mathrm{C}$ and 2 bar of intake temperature and pressure respectively and engine speed of $2000 \mathrm{rpm}$. It can be observed that the maximum pressure was maintained (less than 0.6 bar of difference can be observed). This information is also confirmed by the results obtained from CALMEC, which are more representative as are obtained from the entire set of tests; the given value of compression ratio for the original engine was 14.5:1 while for the modified engine was 13.8:1. Looking at the shape of both curves during the compression stroke it can be observed that the modified engine has a higher polytrophic coefficient. This fact can explain that, even if there exists a difference of compression ratio, the original maximum pressure 
it still being close to the modified one. This leads to higher thermodynamic delays as can be seen on the right top corner of Figure 6, which presents a detail around TDC [41]. The modified engine reaches its maximum peak value almost 1 degree before the original engine. This can be interpreted as the engine has become more adiabatic due to the fact that heat transfer surfaces were slightly modified [42].

\subsection{Local behaviour}

Figure 7(a) presents the measured surface temperature for three of the five thermocouples installed in the combustion chamber walls. Thermocouples $T_{3}$ and $T_{4}$ were not able to operate satisfactorily over the majority of the tests and for that reason its signal is not presented. The mean value of the steady state in-depth temperature is also presented for the three probes. The data were taken with the engine motored at $2000 \mathrm{rpm}$, with intake pressure of 2.5 bar and intake temperature of $25^{\circ} \mathrm{C}$.

The peak surface temperature at location 1 is about $11 \mathrm{~K}$ above its minimum surface value, for location 2 is about 16K, and 19K for location 5 . Even if the temperature swings in the last two locations are similar, lower temperatures along the whole cycle are observed in location 2. This is reasonable, as probe 2 is located near the inlet zone and therefore lower wall temperatures should be expected in comparison with location 5, that is situated on the exhaust zone where higher values are reached. Observing carefully the temporal variation of the wall temperature signal, a little fluctuation produced by the opening of exhaust valve can be noticed, which is due to the changes induced in the fluid motion, and is more evident in the sensor that is near the exhaust valve. The one that is in the middle zone $\left(T_{2}\right)$ does not present 
any noticeable change during valve opening and closing.

Changes in thermodynamic conditions when the clean charge is admitted can be also observed. Specifically, after EVC the wall temperature decreases until it reaches its minimum value for $T_{1}$ and $T_{5}$ probes near the IVC, and with a small delay in the case of $T_{2}$. It may be noticed that the wall surface temperature peaks occur about 10 degrees after TDC for the three thermocouples, while the maximum gas temperature is expected at TDC or even a few degrees before. This observation may be explained by the relative temperatures of the gas and wall. Gas temperature starts decreasing near TDC but it still hotter than the surfaces of the walls, thus, heat will continue flowing from the gas to the walls, and the surface temperature will continue rising until the rate of heat conduction into the inner wall material exceeds that from the gas to the wall [43].

In Figure 7 (b) the heat transfer through the wall-gas interface, computed from the surface temperature variations described above, are shown. Due to the fact that the highest heat transfer rates to the walls take place during the compression an expansion strokes, the data shown has been limited to these strokes. The peak heat transfer reaches a level of $0.29 \mathrm{MW} / \mathrm{m}^{2}$ in the exhaust zone, while in the middle zone of the chamber it is $34 \%$ lower, reaching a level of $0.19 \mathrm{MW} / \mathrm{m}^{2}$.

This confirms the importance of the knowledge on local heat fluxes in the design stages as, the exit zones are much more thermally loaded than others. The probe located in the inlet zone has its maximum in $0.23 \mathrm{MW} / \mathrm{m}^{2}$. The curves of heat flux display asymmetry with respect to TDC, in that they decay slower during the expansion stroke than during the compression 
stroke. This phenomenon can be originated in the gradually decreasing of intensity of the in-cylinder motions caused by wall friction and turbulence decay [44]. In-cylinder pressure is also depicted in Figure 7(b). The peak heat flux occurred slightly before TDC for the three locations when the air temperature and pressure were highest, as expected.

\subsection{Intake pressure influence}

The increase of intake pressure produced a significant increase on peak heat fluxes at the three locations, as can be seen in Figure 8(a-c) where the tests at constant engine speed $(1500 \mathrm{rpm})$ and intake temperature $\left(25^{\circ} \mathrm{C}\right)$ are shown. This is due to two reasons: first, the air temperature and pressure increase producing higher wall temperatures and, secondly the swirl also increases [2]. It was detected in the three locations that not only the surface temperature increases but in-depth temperatures also rise; for example, in the case of location 5 changes of almost 50 degrees were reached between 1 and 2.5 bar.

In Figure 8(b) it is notorious that the peak rise of heat flux is not linear with the rise of the inlet pressure. An increase from 1 to 1.5 bar produces a rise of heat flux peak of only $0.02 \mathrm{MW} / \mathrm{m}^{2}$ whereas the change between 2 and 2.5 bar of inlet pressure produces a change five times larger in the maximum heat flux of $0.1 \mathrm{MW} / \mathrm{m}^{2}$. In the case of Figure 8(a) this tendency is also observed. This can be explained if the mass flow rate and pressure are analysed. For the same two cases, the increment of 0.5 bar in inlet pressure will produce an increase of $27 \%$ in the air mass flow for the first case, while the same increase of pressure in the second case just produces an increment of $2 \%$ in the mass flow. Additionally, the peak of pressure signal (Figure 8(d)) rises 
linearly with the increment of inlet pressure. Since, under motored condition, gas temperature only depends on these two parameters, an abrupt change is to be expected both in the gas and the wall temperatures.

At the beginning of the compression stroke in Figure 8(a) and (c), the heat fluxes corresponding to lower inlet pressure were higher than the upper ones. This can be due to the fact that inlet temperature was kept constant and, therefore, since the mass was increasing with inlet pressure, more energy was needed to rise the charge temperature and hence less heat was transferred to the walls.

\subsection{Wall temperature influence}

Figure 9(a) shows the instantaneous surface temperature and heat flux variation with coolant temperature for the three probes. The combustion chamber wall temperature was varied by controlling the coolant and oil temperatures to $60^{\circ} \mathrm{C}$ and $70^{\circ} \mathrm{C}$, while all other parameters were maintained constant to $2500 \mathrm{rpm}, 25^{\circ} \mathrm{C}$ of inlet temperature, and 2 bar of inlet pressure. The surface temperatures decrease linearly as the coolant temperature decreases at the three locations. The zone with higher surface temperature it still being located near the exhaust valve, while the lower temperature is near the inlet. Differences of $160^{\circ} \mathrm{C}$ between the coolant and the hottest spot of the walls are reached, this can seem quite high, but is normal as the elongation piece it is not directly cooled.

Figure 9(b) shows the heat flux of the three probes for the two coolant temperatures. As soon as the coolant temperature decreases, the local heat flux decreases as well. This might seem counter-intuitive, but it may be due to the fact that the gas temperature is the main driver in the transient heat 
transfer process. While in zones 1 and 5 the variation of the fluxes when the coolant temperature is risen, is more notorious, in zone 2 is almost negligible, which is an indication of the uneven behaviour of the thermal boundary layer in combustion engines. At the peak of heat fluxes a small delay can be noticed for the hotter cooling temperatures. This might be due to the time that the surface temperature will take to equal the gas temperature, longer with lower wall values.

\subsection{Engine speed influence}

Inside the cylinder, heat transfer under motored conditions changes with engine speed because of several reasons: with an increase in engine speed, the gas motion increases and thus the convection coefficient; but as engine speed rises, the engine also becomes more adiabatic as there is less time to exchange energy. Engine speed also affects volumetric efficiency, producing changes in pressure, temperature and mass values in the IVC and consequently in the evolution of heat transfer during the entire cycle.

Figure 10(a) shows the temperature swings variation on location 1 with different engine speeds for five motored tests in which the inlet density was kept constant to $1.75 \mathrm{~kg} / \mathrm{m}^{3}$. The other two locations are not plotted because their behaviours are similar. The increment of engine speed produces a rise in both wall temperatures, in depth and surface. This is reasonable as from 1000 until $2000 \mathrm{rpm}$ the maximum peak of pressure (Figure 10(c)) rises gradually as the engine speed increases, while the mass remains almost constant. In the case of 2500 and $3000 \mathrm{rpm}$, though, the maximum pressure decreases down to the value of the 2000 and $1000 \mathrm{rpm}$ test, respectively, the total mass in the cylinder is almost $20 \%$ and $40 \%$ lower and, as a result, the temperature 
in the case of 2500, almost remain constant and in the case of 3000 suddenly increases.

Figure 10(b) shows the heat flux through the walls calculated for the five engine speeds, and the tendency is to increase with the speed, as expected, owing to the turbulence and velocities are higher. The big diference between the two

\section{Summary and Conclusions}

An original experimental approach to study of the gas-wall local heat transfer on the walls of the combustion chamber of a Diesel engine was presented. The experimental device was designed and constructed in order to recreate the main features of a real engine. The first set of instantaneous temperature and heat transfer measurements indicate that the data obtained is consistent and coherent with previous works performed by other researchers. This means that not only the experimental facility had been validated but also that the methodology and processing tools are set up to estimate heat losses in fired conditions.

Parametric studies were performed in order to evaluate the effect of the most important engine parameters. These should be useful in upcoming studies aiming at proposing and verifying new heat transfer models based on a combination of experimental and numerical computational work based on fluid dynamic simulations. From the studies presented on independent variations of inlet pressure, engine speed, and coolant temperature the following conclusions may be drawn:

- The heat transfer through the combustion chamber is strongly affected 
by the air consumption.

- The transient heat transfer is strongly affected by the gas temperature rather than by the inner wall temperatures.

- In order to evaluate engine speed influence it is not enough to keep the inlet density constant, but it is also necessary to take into account the volumetric efficiency effects.

- Engine heat transfer is not uniform in the different walls of the combustion chamber due to the irregular behaviour of the thermal boundary layer.

\section{Acknowledgements}

Authors would like to thank Daniel Lerida for his technical support and help with the experimental work. 
[1] W.J.D. Annand, T.H. Ma, Instantaneous heat transfer rates to the cylinder head surface of a small compression-ignition engine, Proc. Instn. Mech. Eng. 185 (1970-71) 976-987.

[2] C.R. Mure, K.T. Rhee, Instantaneous heat transfer over the piston of a motored direct injection-type Diesel engine, SAE Paper 890469 (1989).

[3] G. Woschni, A universally applicable equation for the instantaneous heat transfer coefficient in the internal combustion engine, SAE Paper 670931 (1967) Warrendale, PA: Society of Automotive Engineers Inc.

[4] G. Borman, K. Nishiwaki, Internal combustion engine heat transfer, Prog. Energy Combust. Sci. 13 (1987) 1-46.

[5] J.B. Heywood, Internal combustion engine fundamentals, International Edition, MacGraw-Hill. Singapore (1988) 668-711.

[6] E.G. Giakoumis, Cylinder wall insulation effects on the first- and secondlaw balances of a turbocharged diesel engine operating under transient load conditions, Energy Conv. Manag. 48 (2007) 2925-2933.

[7] T. Morel, S. Wahiduzzaman, E.F. Fort, D.R. Tree, D.P. DeWitt, K.G. Kreider, Heat transfer in a cooled and an insulated Diesel engine, SAE paper 890572. (1989) Warrandale, PA: Society of Automotive Engineers Inc.

[8] H. Hazar, Characterization and effect of using cotton methyl ester as fuel in a LHR diesel engine, Energy Conv. Manag. 52 (2011) 258-263 
[9] C.D. Rakopoulos, E.G. Giakoumis, D.C. Rakopoulos, Cylinder wall temperature effects on the transient performance of a turbocharged Diesel engine, Energy Conv. Manag. 45 (2004) 2627-2638.

[10] A. Broatch, J.M. Lujan, J.R. Serrano, B. Pla, A procedure to reduce pollutant gases from Diesel combustion during European MVEG-A cycle by using electrical intake air-heaters, Fuel 87-12 (2008) 2760-2778.

[11] A.J. Torregrosa, P. Olmeda, J. Martn, B. Degraeuwe, Experiments on the influence of inlet charge and coolant temperature on performance and emissions of a DI Diesel engine, Exp. Therm. Fluid Sci. 30-7 (2006) 633-641.

[12] D.L. Allen, M.P. Lasecki, Thermal management evolution and controlled coolant flow, SAE paper 2001-01-1732 (2001).

[13] A.J. Torregrosa, A. Broatch, P. Olmeda, C. Romero, Assessment of the influence of different cooling system configurations on engine warm-up, emissions and fuel consumption, Int. J. Automot. Technol. 9-4 (2008) 447-458.

[14] T. Thurnheera, D. Edenhausera, P. Soltica, D. Schreibera, P. Kirchenb and A. Sankowskic, Experimental investigation on different injection strategies in a heavy-duty diesel engine: Emissions and loss analysis, Energy Conv. Manag. 52 (2011) 457-467

[15] C.D. Rakopoulos, D.T. Hountalas, Development and validation of a 3D multi-zone combustion model for the prediction of DI diesel engine performance and pollutants emissions, SAE paper 981021 (1998). 
[16] F. Payri, S. Molina, J. Martn, O. Armas, Influence of measurement errors and estimated parameters on combustion diagnosis, Appl. Therm. Eng. 26 (2006) 226-236.

[17] C.D. Rakopoulos, D.C. Rakopoulos, E.G. Giakoumis, D.C. Kyritsis, Validation and sensitivity analysis of a two zone Diesel engine model for combustion and emissions prediction, Energy Conv. Manag. 45 (2004) 1471-1495.

[18] A.J. Torregrosa, P. Olmeda, J. Martín, C. Romero, A Tool for Predicting the Thermal Performance of a Diesel Engine, Heat Transfer Engineering, 32 (2011), 891904.

[19] C.A. Finol, K. Robinson, Thermal modelling of modern engines: a review of empirical correlations to estimate the in-cylinder heat transfer coefficient, IMechE. 220-D (2006) 1765-1781.

[20] C.F. Taylor, T.Y. Toong, Heat transfer in internal-combustion engines, ASME paper 57-HT-17-1957 (1957).

[21] W.J. Annand, Heat transfer in the cylinders of reciprocating internal combustion engines, Proc. Instn. Mech. Engrs. 177-36 (1963) 973-990.

[22] G. Hohenberg, Advanced approaches for heat transfer calculations, SAE Trans. 88, SAE paper 790825 (1979).

[23] J.C. Dent, S.J. Suliaman, Convective and radiative heat transfer in a high swirl direct injection diesel engine, SAE Trans. 86, SAE paper 770407 (1977). 
[24] T. LeFeuvre, P.S. Myers, O.A. Uyehara, Experimental instantaneous heat fluxes in a diesel engine and their correlation, SAE Trans. 78, SAE paper 690464. (1969).

[25] C.D. Rakopoulos, E.G. Giakoumis, D.C. Rakopoulos, Study of the shortterm cylinder wall temperature oscillations during transient operation of turbo-charged diesel engine with various insulation schemes, Int. J. of Engine Research 9 (2008) 177-193.

[26] F. Payri, X. Margot, A. Gil, J. Martín, Computational study of heat transfer to the walls of a diesel engine, SAE-2005-01-0210 (2005).

[27] H.W. Wu, S.W. Perng, Numerical analysis of thermal turbulent flow in the bowl-in-piston combustion chamber of a motored engine, Int. J. Therm. Sci. 43 (2004) 1011-1023.

[28] C.D. Rakopoulos, G.M. Kosmadakis, E.G. Pariotis, Investigation of piston bowl geometry and speed effects in a motored HSDI diesel engine using a CFD against a quasi-dimensional model, Energy Conv. Manag. 51 (2010) 470-484

[29] C.D. Rakopoulos, G.M. Kosmadakis, E.G. Pariotis, Critical evaluation of current heat transfer models used in CFD in-cylinder engine simulations and establishments of comprehensive wall-function formulation, Appl. Energ. 87 (2010) 1612-1630.

[30] B. Jayashankaraa, V. Ganesan, Effect of fuel injection timing and intake pressure on the performance of a DI diesel engine - A parametric study using CFD, Energy Conv. Manag. 51 (2010) 1835-1848 
[31] E. Piccini, S.M. Guo, T.V. Jones, The development of a new directheat-flux gauge for heat-transfer facilities, Meas. Sci. Technol. 11 (2000) 342-349.

[32] D.R. Buttsworth, R. Stevens, C.R. Stone. Eroding ribbon thermocouples: impulse response and transient heat flux analysis, Meas. Sci. Technol. 16 (2005) 1487-1494.

[33] J. Ninigian, D. Ninigian. A unique thermocouple to measure the temperature of squibs, igniters, propellants and rocket nozzles, SPIE Paper 6222-3 (2007).

[34] X. Wang, P. Price, C.R. Stone, D. Richardson, Heat release and flux in a spray-guided direct-injection gasoline engine, IMechE. 221-D (2007) 1441-1452.

[35] J. Chang, O. Gralp, Z. Filipi, D. Assanis, T. W. Kuo, P. Najt, R. Rask, New heat transfer correlations for an HCCI engine derived from measurements of instantaneous surface heat flux, SAE paper 2004-012996 (2004).

[36] J.M. Desantes, A.J. Torregrosa, A. Broatch, P. Olmeda, Experiments on the influence of intake conditions on local instantaneous heat flux in reciprocating internal combustion engines, Energy 36 (2011) 60-69

[37] J. Chang, Z. Filipi, D.N. Assanis, P. Najt, R. Rask, Characterizing the thermal sensitivity of gasoline homogeneous charge compression ignition engine with measurement of instantaneous wall temperature and heat flux, Int. J. Eng. Res. 6-4 (2005) 289-309. 
[38] C.D. Rakopoulos, G.C. Mavropoulos, Experimental evaluation of local instantaneous heat transfer characteristics in the combustion chamber of air-cooled direct injection diesel engine. Energy. 33 (2008) 1084-1099.

[39] F. Payri, P. Olmeda, J. Martín, A. García, A complete 0D thermodynamic predictive model for direct injection diesel engines. Appl Energy (2011), doi:10.1016/j.apenergy.2011.06.005.

[40] F. Payri, P. Olmeda, C. Guardiola, J. Martín. Adaptive determination of cut-off frequencies for filtering the in-cylinder pressure in Diesel engines combustion analysis, Applied Thermal Engineering 31 (2011), 2869-2876

[41] M. Lapuerta, O. Armas, S. Molina, Study of the compression cycle of a reciprocating engine through the polytropic coefficient, Appl. Therm. Eng. 23 (2003) 313-323.

[42] D.T. Hountalas, G.C. Mavropoulos, G. Kourbetis, Experimental investigation to develop a methodology for estimating the compression condition of DI Diesel engines, Energy Conv. Manag. 47 (2006) 1-18.

[43] V.D. Overbye, J.E. Bennethum, O.A. Uyehara, P.S. Myers, Unsteady heat transfer in engines, Trans. SAE 69 (1961) 461-492.

[44] T. Morel, S. Wahiduzzaman, D.R. Tree, D.P. DeWitt, Effect of speed, load, and location on heat transfer in a Diesel engine - Measurements and predictions, SAE paper 870154 (1987) 125-136. 


\section{List of figures}

Fig. 1. Sketch of the final combustion chamber configuration (not to scale). Fig. 2. Elongation piece with combustion chamber, heat flux sensors and pressure transducer housing: (a) Final design, (b) Final constructed piece.

Fig. 3. Schematic diagram of the experimental facility and data acquisition system.

Fig. 4. Heat flux probe design.

Fig. 5. Flowchart of the methodology applied to perform engine heat transfer analysis.

Fig. 6. In-cylinder pressures of original engine configuration (black) and of modified configuration (gray) for a motored cycle at $2000 \mathrm{rpm}$ and $25^{\circ} \mathrm{C}$ of inlet temperature and 2 bar of inlet pressure.

Fig. 7. (a) Local temperature swings and (b) local heat fluxes and pressure measured at 2000rpm engine speed and 2.5 bar of inlet pressure and $25^{\circ} \mathrm{C}$ of inlet temperature.

Fig. 8. (a-c) Local heat fluxes measured at different locations at $1500 \mathrm{rpm}$ and $25^{\circ} \mathrm{C}$ of inlet temperature (d) and in-cylinder pressure with different inlet pressure.

Fig. 9. (a) Temperature profiles and (b) heat fluxes at three locations with $60^{\circ} \mathrm{C}$ (full line) and $70^{\circ} \mathrm{C}$ (dash line) at $2500 \mathrm{rpm}, 2 \mathrm{bar}$, and $25^{\circ} \mathrm{C}$ of inlet pressure and temperature.

Fig. 10. (a) Temperature swings, (b) heat fluxes, and (c) in-cylinder pressure signal for five different speeds on location 1. 


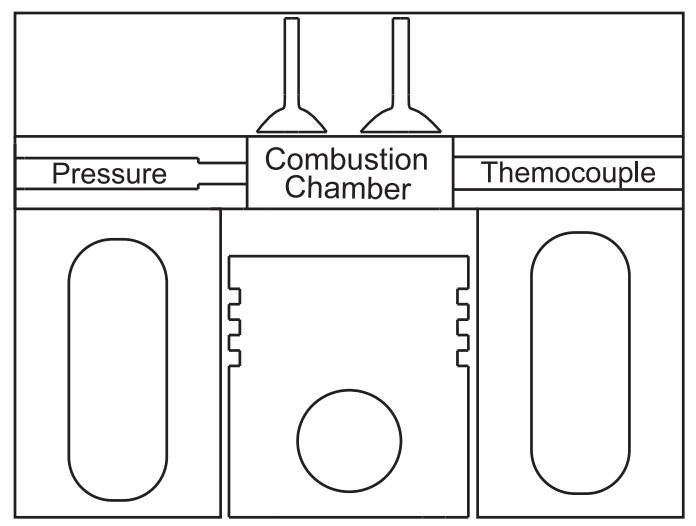

Figure 1: Sketch of the final combustion chamber configuration (not to scale) 

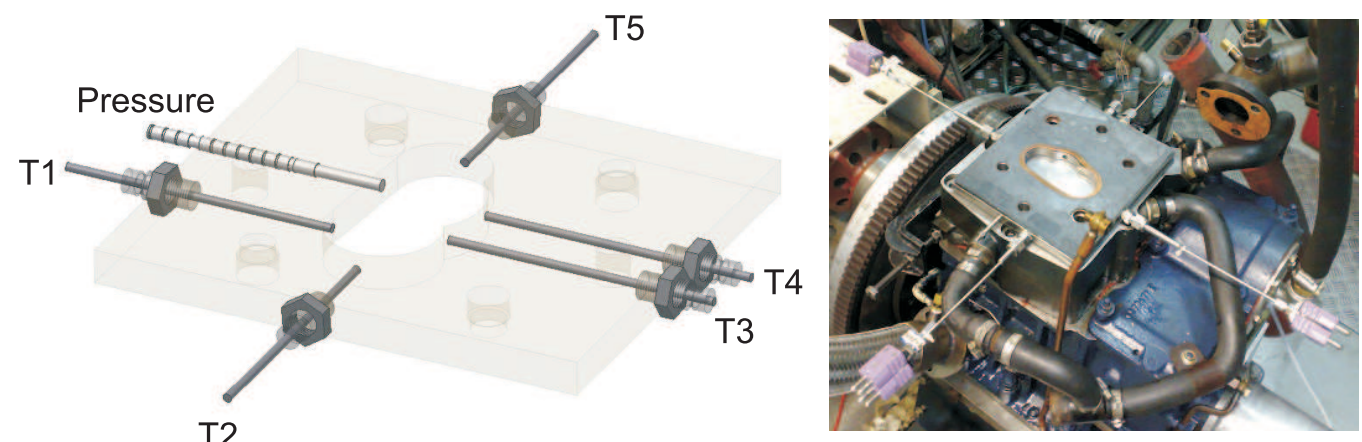

Figure 2: Elongation piece with combustion chamber, heat flux sensors and pressure transducer housing: (a) Final design, (b) Final constructed piece. 


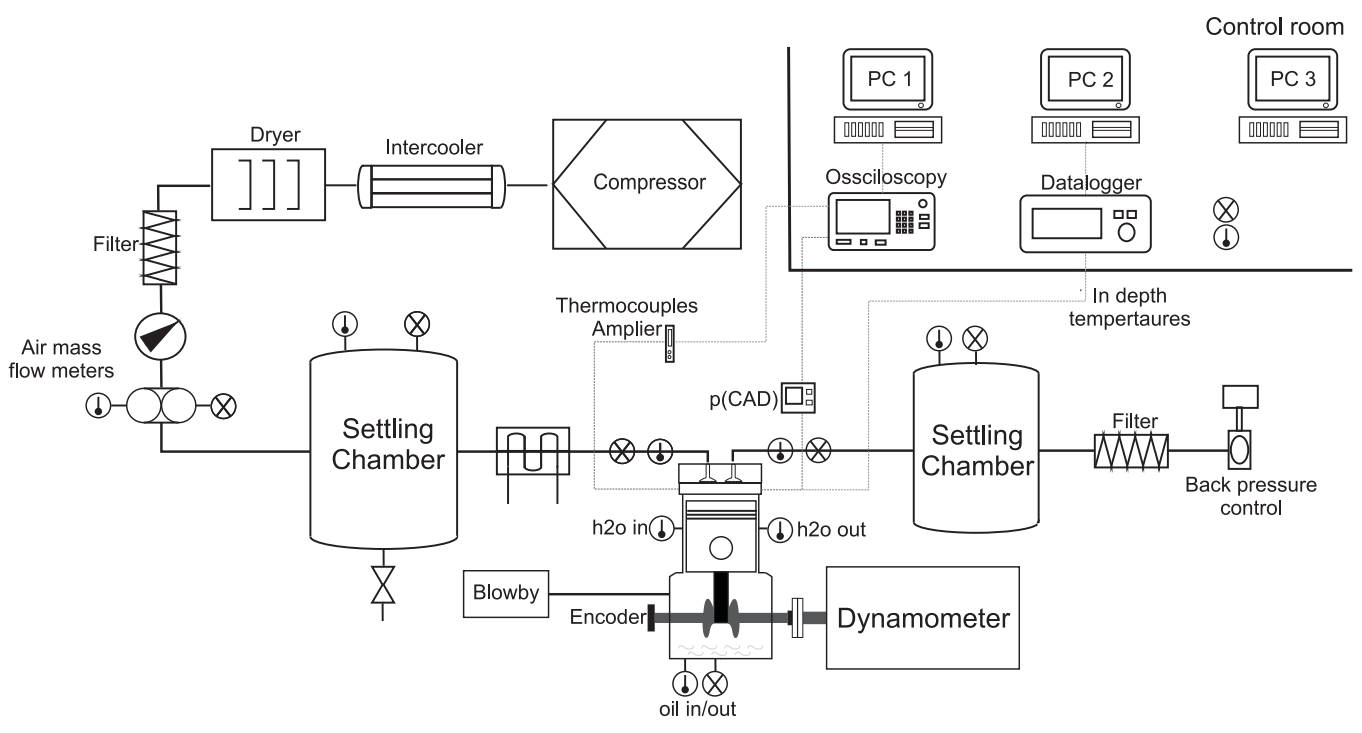

Figure 3: Schematic diagram of the experimental facility and data acquisition system. 


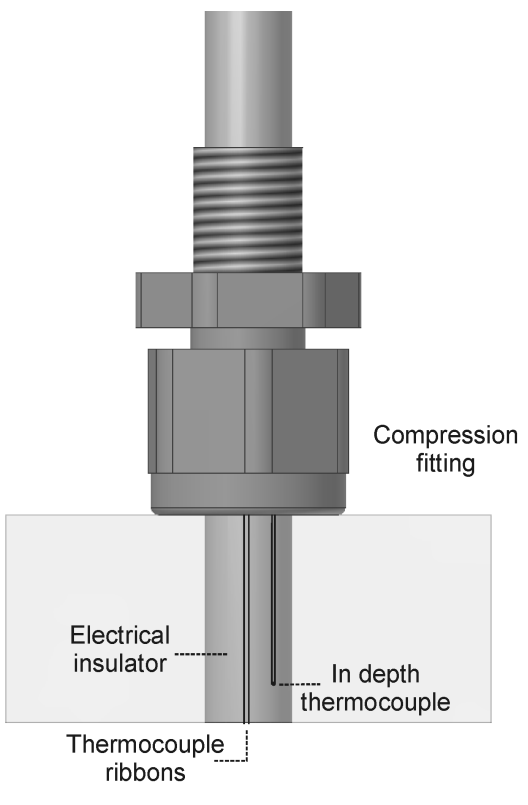

Figure 4: Heat flux probe design. 


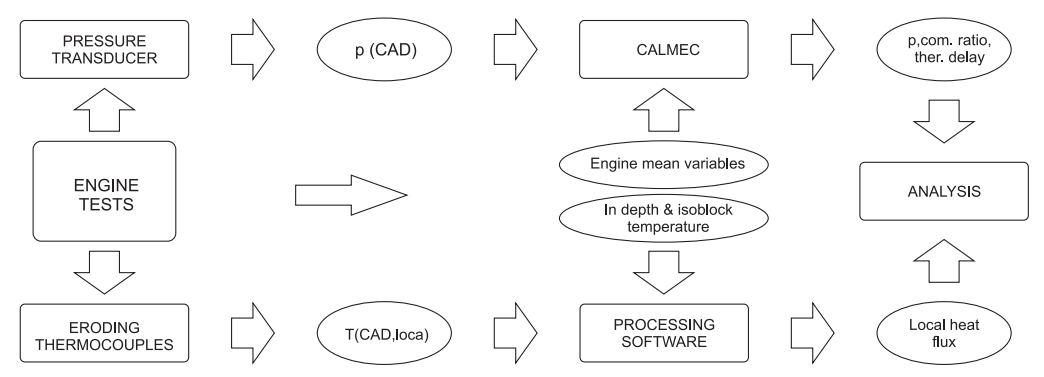

Figure 5: Flowchart of the methodology applied to perform engine heat transfer analysis. 


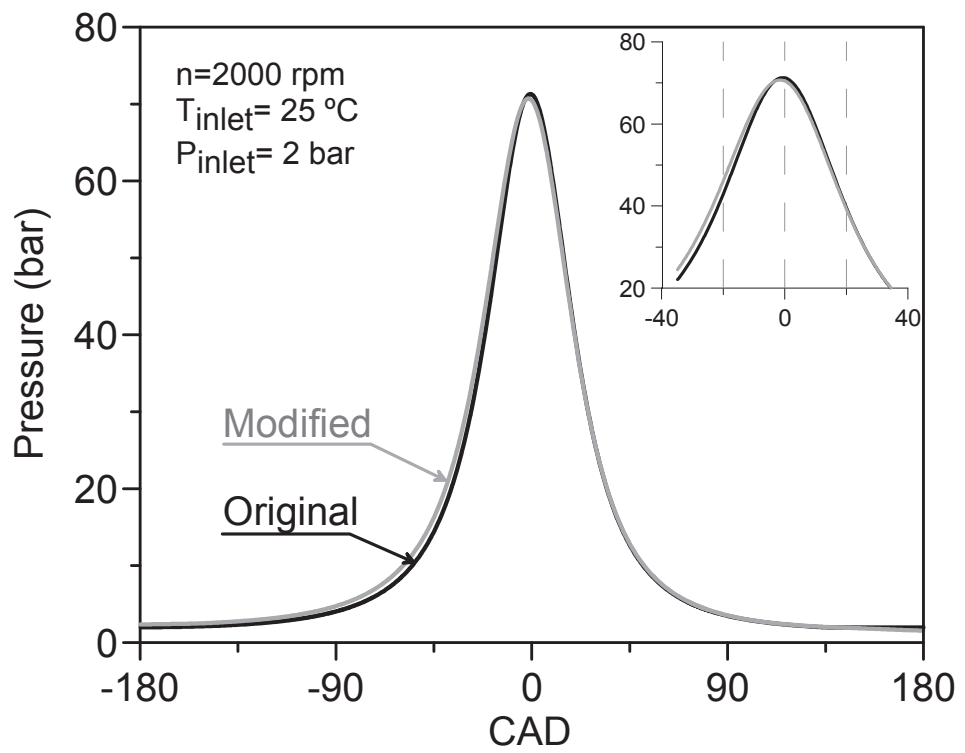

Figure 6: In-cylinder pressures of original engine configuration (black) and of modified configuration (gray) for a motored cycle at $2000 \mathrm{rpm}$ and $25^{\circ} \mathrm{C}$ of inlet temperature and 2 bar of inlet pressure. 

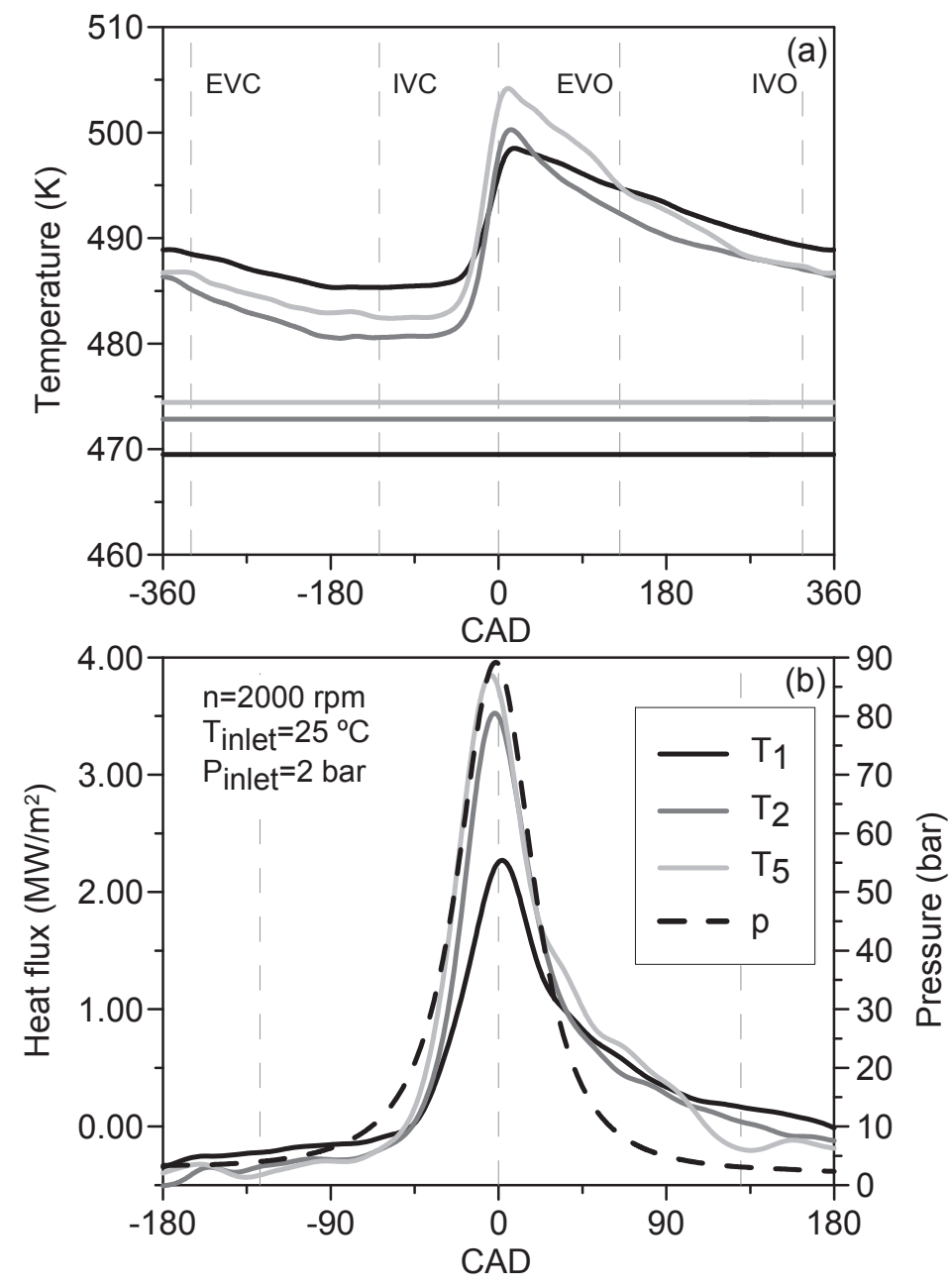

Figure 7: (a) Local temperature swings and (b) local heat fluxes and pressure measured at 2000rpm engine speed and 2.5 bar of inlet pressure and $25^{\circ} \mathrm{C}$ of inlet temperature. 

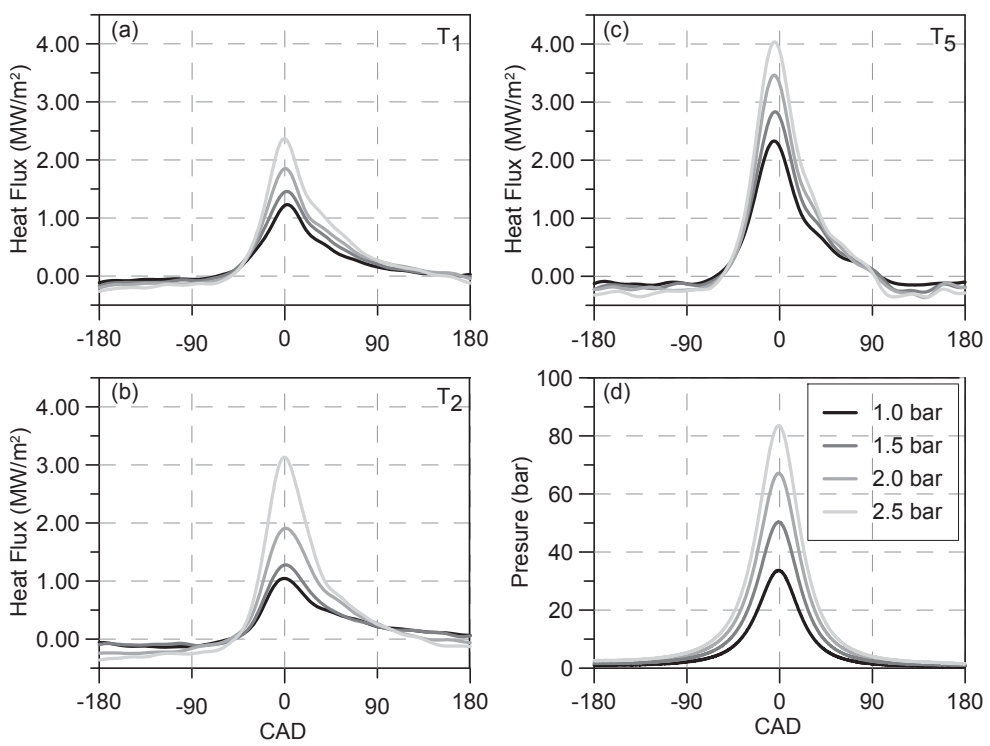

Figure 8: (a-c) Local heat fluxes measured at different locations at $1500 \mathrm{rpm}$ and $25^{\circ} \mathrm{C}$ of inlet temperature (d) and in-cylinder pressure with different inlet pressure. 


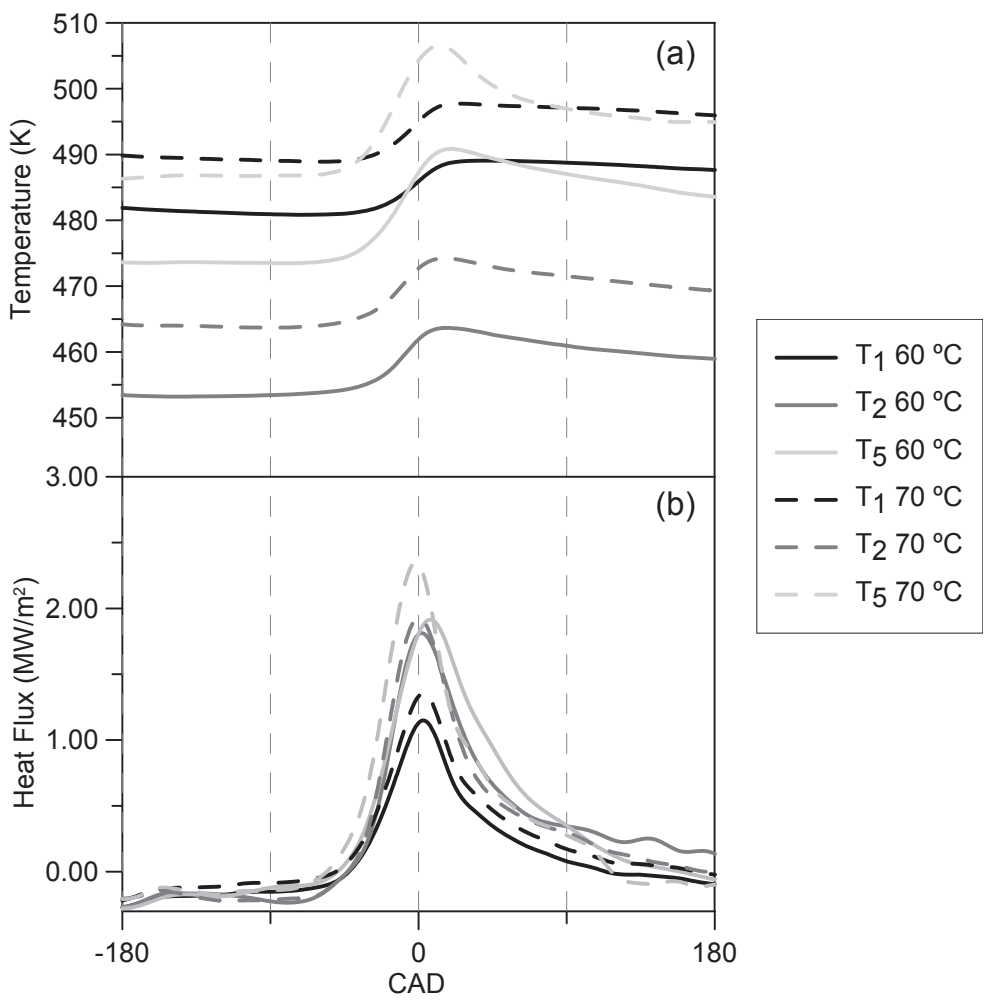

Figure 9: (a) Temperature profiles and (b) heat fluxes at three locations with $60^{\circ} \mathrm{C}$ (full line) and $70^{\circ} \mathrm{C}$ (dash line) at $2500 \mathrm{rpm}, 2$ bar, and $25^{\circ} \mathrm{C}$ of inlet pressure and temperature. 


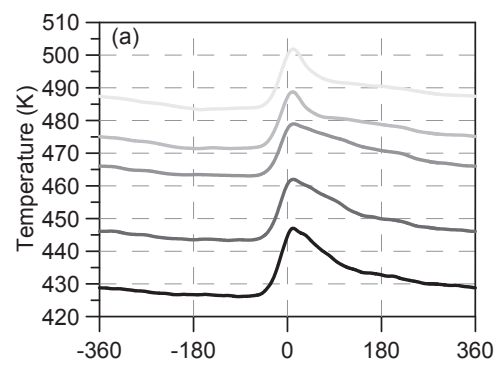

$$
\begin{aligned}
& \text { In depth temperatures } \\
& \text { - } 1000 \mathrm{rpm} \quad 412 \mathrm{~K} \\
& \text { - } 1500 \mathrm{rpm} \quad 427 \mathrm{~K} \\
& \text { - } 2000 \mathrm{rpm} 442 \mathrm{~K} \\
& \text { - } 2500 \mathrm{rpm} \quad 448 \mathrm{~K} \\
& 3000 \mathrm{rpm} \quad 467 \mathrm{~K}
\end{aligned}
$$
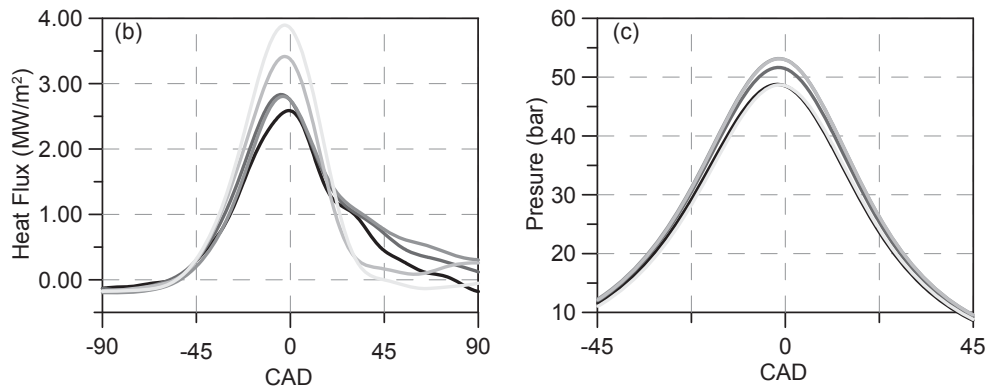

Figure 10: (a) Temperature swings, (b) heat fluxes, and (c) in-cylinder pressure signal for five different speeds on location 1. 


\section{${ }_{628}$ List of tables}

629

${ }_{630}$ Table 1. Engine geometric characteristics.

${ }_{631}$ Table 2. Motoring tests.

632 
Table 1: Engine geometric characteristics.

\begin{tabular}{ccc}
\hline Engine type & & Single cylinder, four-stroke, water cooled \\
\hline Displacement & $(\mathrm{l})$ & 0.573 \\
Bore/Stroke & $(\mathrm{mm})$ & $90 / 90$ \\
Original compression ratio & $14.5: 1$ \\
Modified compression ratio & & $13.8: 1$ \\
Maximun speed & $(\mathrm{rpm})$ & 4000 \\
Inlet/Exhaust valve diameter & $(\mathrm{mm})$ & $41.7 / 34.712$ \\
Inlet/Exhaust valve opening & $(\mathrm{CAD})$ & $70 \mathrm{bTDC} / 42.5 \mathrm{bBDC}$ \\
Inlet/Exhaust valve closing & $(\mathrm{CAD})$ & $40 \mathrm{aTDC} / 72.5 \mathrm{aBDC}$ \\
\hline
\end{tabular}


Table 2: Motoring tests.

\begin{tabular}{ccc}
$\begin{array}{c}\text { Engine speed } \\
(\mathrm{rpm})\end{array}$ & $\begin{array}{c}\text { Intake pressure } \\
(\mathrm{bar})\end{array}$ & $\begin{array}{c}\text { Cooling water temperature } \\
\left({ }^{\circ} \mathrm{C}\right)\end{array}$ \\
\hline 1000 & & \\
1500 & 1 & 60 \\
2000 & 1.5 & 70 \\
2500 & 2 & \\
3000 & 2.5 & \\
\hline
\end{tabular}

